aerofaciens had a complete opposite effect. Suppression of arthritis by P histicola was dependent on an increase in the numbers of CD103+ dendritic cells, myeloid suppressors, CD11b+Gr-1, and T regulatory cells, CD4+CD25+FoxP3+, in the gut as well as systemically. This led to reduction in $\mathrm{TH} 17$ response while increasing IL-10. On the other hand, C. aerofaciens gavage increased expression of IL-17 and regulatory chemokines as compared to controls. DQ8 mice gavaged with intestinal microbes of arthritis-resistant mice developed arthritis with lower incidence and had skewed Th17/Th2 response.

Conclusions: Our studies suggest that gut commensals influence immune response in and away from the gut. Commensals and their products may provide novel targets for therapeutic strategies in arthritis.

Acknowledgements: Funds were provided by the Department of Defense and Mayo Center of Individualized Medicine

Disclosure of Interest: None declared

DOI: 10.1136/annrheumdis-2017-eular.2307

\section{FRI0078 ADENOSINMONOFOSFAT-AKTIVACTIVATING PROTEIN KINASE (AMFK) - THE BIOPOWER REGULATOR OF AN AUTOPHAGY IN RHEUMATOID ARTHRITIS (PA)}

V.I. Shihkin, G.V. Kudriavtseva, V.V. Shishkin, Y.A. Malenkov. Saint Petersburg state University, Saint Petersburg, Russian Federation

Background: Rheumatoid arthritis is an autoimmune disease characterized by altered cellular homeostasis. A great role of an autophagy is expected in the pathogenesis of these changes.

Objectives: To assess the functional activity of AMFK as a strategic biopower regulator of an autophagy and specific indicator of red-ox potential of cells in the sinovial fluid (SF) of patients with rheumatoid arthritis (RA).

Methods: SF of knee joints of 7 RA patients with active synovitis and 5 donors were investigated. Activity of enzymes was measured in cytosol of SF cells after ultracentrifugation. Activity of AMFK was estimated with the Western blotting method. The consumption speed of oxygen by SF cells was recorded polarographycally using as the substrate glutamic acid $(5 \mu \mathrm{mol} / \mathrm{ml}$ in incubation fluid). Registration of the active forms of oxygen was carried out by EPR (electronic paramagnetic resonance). Levels of adenylic nucleotides were determined chromatographically.

Results: In RA SF we noted activation of AMFK (on average by 2,5 times) at the considerable increase of the AMP level and decrease in ADP and ATP.

Conclusions: These data demonstrate transition of cells of SF in RA to the energy saving mode of functioning that is followed by strengthening of oxidizing processes, deep dissociation of respiration with oxidizing phosphorylation and sharp increase of oxigen consumption speed by SF cells in vitro against the background of the progressing hypoxia of synovial cells and chondrocytes in vivo. Destabilization of mitochondrial and lysosomal membranes of SF cells appears against the background of shift of $\mathrm{pH}$ in RA in more acidic zone. It leads to the reinforced formation of the active forms of oxygen (short-lived toxiferous hydroxyl radicals), shift of red-ox potential of cells, activation of lysosomal hydrolyzing enzymes that forms biochemical mechanisms of development of an autophagy in RA

Disclosure of Interest: None declared

DOI: 10.1136/annrheumdis-2017-eular.5025

\section{FRI0079 TAS5315, A NOVEL BRUTON'S TYROSINE KINASE INHIBITOR, IMPROVE BONE MINERAL DENSITY (BMD) AND BONE EROSION VIA INHIBITION OF OSTEOCLAST ACTIVATION IN MURINE MODEL FOR RHEUMATOID ARTHRITIS}

Y. Yoshiga, F. Hosoi, S. Iguchi, R. Kaneko, Y. Nakachi, D. Akasaka, K. Tanaka, K. Yonekura, T. Utsugi, E. Sasaki, Y. Iwasawa. Taiho Pharmaceutical, Ibaraki, Japan

Background: The erosions of bone and cartilage are a cardinal feature of rheumatoid arthritis (RA) and associated with disease severity and poor functional outcome $^{1}$. Although several anti-inflammatory drugs improve symptoms of articular inflammation, they are less effective against bone erosion. The bone erosions in RA are associated with aberrant activations of osteoclasts induced by pro-inflammatory cytokines and receptor activator of nuclear factor $\kappa \mathrm{B}$ ligand (RANKL) ${ }^{2}$. Bruton's tyrosine kinase (BTK), which is expressed in immune cells and mature osteoclast, is reported to be a key molecule in inflammatory response and bone resorption ${ }^{3,4}$. Thus, targeting BTK may be efficacious against not only inflammation but also bone erosion through direct regulation of activation of effector cells such as B cells, macrophages and osteoclasts in RA

Objectives: In this study, we evaluated the effect of TAS5315, a novel BTK inhibitor, on in vitro osteoclasts activation and bone erosion in mouse collageninduced arthritis.

Methods: Kinase selectivity of TAS5315 was assessed by available kinase assay panels. The effects of TAS5315 on macrophages and osteoclasts were assessed by examining phosphorylation of BTK, cytokine productions, osteoclast differentiation and bone resorptions. The effects of TAS5315 were investigated in mouse collagen-induced arthritis (CIA). Disease severity was evaluated by clinical score of paw swelling. Changes in bone mineral density (BMD) and bone erosion were assessed using microCT. TNF blocker was used as a control drug.

Results: TAS5315 selectively inhibited the enzyme activity of BTK and had less off target inhibition against other kinases. TAS5315 dose-dependently inhibited cytokine productions by macrophages, phosphorylation of BTK, osteoclastogenesis and bone resorbing activity in osteoclasts. In established mouse CIA, TAS5315 significantly ameliorated paw swelling in a dose dependent manner and the anti-inflammatory effect of TAS5315 $(0.3 \mathrm{mg} / \mathrm{kg}$, once daily) was comparable to that of TNF blocker. Most importantly, improvement of BMD and bone erosion were observed in TAS5315 treated mice at a doses of higher than $0.1 \mathrm{mg} / \mathrm{kg}$ within 13 days from treatment initiation, but not in TNF blocker-treated mice. The onset of action of TAS5315 on BMD and bone erosion was earlier and stronger compared with that of TNF blocker. These data suggest that TAS5315 had direct effect against osteoclasts function and led to improvement of bone erosion in murine model for RA.

Conclusions: Our study demonstrates that TAS5315, a novel BTK inhibitor, would be an ideal RA therapeutic agent that could inhibit bone destruction as well as inflammation.

References:

[1] Nat Rev Rheumatol. 2012;8,656-64.

[2] Nat Rev Rheumatol. 2015;11,189-94.

[3] Cell. 2008;132,794-806.

[4] Drug Discov Today. 2014;19,1200-4

Disclosure of Interest: None declared

DOI: 10.1136/annrheumdis-2017-eular.1761

\section{FRI0080 CD11B+GR1DIM TOLEROGENIC DENDRITIC CELL-LIKE CELLS ARE EXPANDED IN INTERSTITIAL LUNG DISEASE IN SKG MICE}

S. Sendo, J. Saegusa, Y. Ichise, H. Yamada, I. Naka, T. Okano, S. Takahashi, Y. Ueda, K. Akashi, A. Onishi, A. Morinobu. Department of Rheumatology and Clinical Immunology, Kobe University Graduate School of Medicine, Kobe City, Japan

Background: SKG mice develop interstitial lung disease (ILD) resembling human rheumatoid arthritis (RA)-associated ILD. We identified a unique cell population of $\mathrm{CD} 11 \mathrm{~b}^{+} \mathrm{Gr} 1^{\text {dim }}$ cells in the severely inflamed lungs in SKG mice.

Objectives: The aims of this study are to clarify the mechanism behind the lung pathology, and to elucidate the phenotype and function of $C D 11 b^{+} \mathrm{Gr} 1^{\text {dim }}$ cells in ILD-induced SKG mice.

Methods: We assessed the severity of zymosan A-induced ILD in SKG mice histologically, and examined lung-infiltrating cells by Giemsa stain and flow cytometry. Total lung cells and isolated monocytic myeloid-derived suppressor cells (M-MDSCs) were cultured in vitro with GM-CSF (and IL-4). The proliferation of CSFE-labeled naïve T cells co-cultured with isolated $\mathrm{CD} 11 \mathrm{~b}^{+} \mathrm{Gr} 1^{\text {dim }}$ cells and MDSCs was evaluated by flow cytometry.

Results: MDSCs, Th17 cells, and group 1 and 3 innate lymphoid cells (ILC1s and ILC3s) were increased in the lungs; the proportion of these cells varied with ILD severity. In this process, we found that a unique cell population, CD11b+Gr1dim cells, were expanded in the severely inflamed lungs (Figure). About half of the $\mathrm{CD} 11 \mathrm{~b}^{+} \mathrm{Gr}$ dim $^{\mathrm{dim}}$ cells expressed $\mathrm{CD} 11 \mathrm{c}$ and Giemsa stain revealed that they were morphologically dendritic cell (DC)-like. The CD11 b+Gr1dim cells were induced from M-MDSCs with GM-CSF in vitro and were considered tolerogenic because they expressed high levels of PD-L1 and suppressed T-cell proliferation. The CD $11 b^{+} G r 1^{\text {dim }}$ cells have never described previously and termed CD $11 b^{+}$Gr $1^{\text {dim }}$

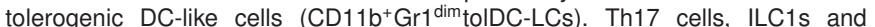
ILC3s in the inflamed lung produced GM-CSF, which in turn could induce



Conclusions: We identified a unique cell population, termed CD $11 b^{+} \mathrm{Gr} 1^{\operatorname{dim}}$ tolDCLCs, in ILD-induced lungs in SKG mice.

\section{References:}

[1] Nishimura K, Saegusa J, Matsuki F, Akashi K, Kageyama G, Morinobu A. Tofacitinib facilitates the expansion of myeloid-derived suppressor cells and ameliorates arthritis in SKG mice. Arthritis Rheumatol 2015;67:893-902.

[2] Shiomi A, Usui T, Ishikawa Y, Shimuzu M, Murakami K, Mimori T. GM-CSF but not IL-17 is critical for the development of severe interstitial lung disease in SKG mice. J. Immunol 2014;193:849-59.

[3] Takenaka MC, Quintana FJ. Tolerogenic dendritic cells. Semin. Immunopahol 2016. doi:10.1007/s00281-016-0587-8.

Acknowledgements: The authors thank Shino Tanaka (Department Rheumatology and Clinical Immunology, Kobe University Graduate School of Medicine) for providing technical assistance.

Abstract FRI0078 - Table 1 AMPK activity (units/mg of protein), oxygen uptake rate (OUR, natoms of oxygen/min/mg of protein), the level of active free radical form of oxygen (AFRF, units/mg of protein), the content of adenine nucleotides in SF ( $\mathrm{nmol} / \mathrm{ml})$ and $\mathrm{pH}$ in SF in RA

\begin{tabular}{|c|c|c|c|c|c|c|c|}
\hline & AMPK & OUR & AFRF & AMP & $A D P$ & AFP & $\mathrm{pH}$ of $\mathrm{SF}$ \\
\hline RA SF & $2,5 \pm 0,4$ & $86,3 \pm 4,3$ & $32,8 \pm 4,6$ & $120-135(127,5)$ & $97-123(110)$ & $735-990(862,5)$ & $66,4-6,97(6,81)$ \\
\hline Donor SF & $1,1 \pm 0,2$ & $42,4 \pm 3,7$ & $10,9 \pm 2,1$ & $45-81(63)$ & $157-294(222,5)$ & $1490-1547(1518,5)$ & $7,43-7,65(7,54)$ \\
\hline
\end{tabular}

